Nevşehir Bilim ve Teknoloji Dergisi (2021), 10(2) 67-72

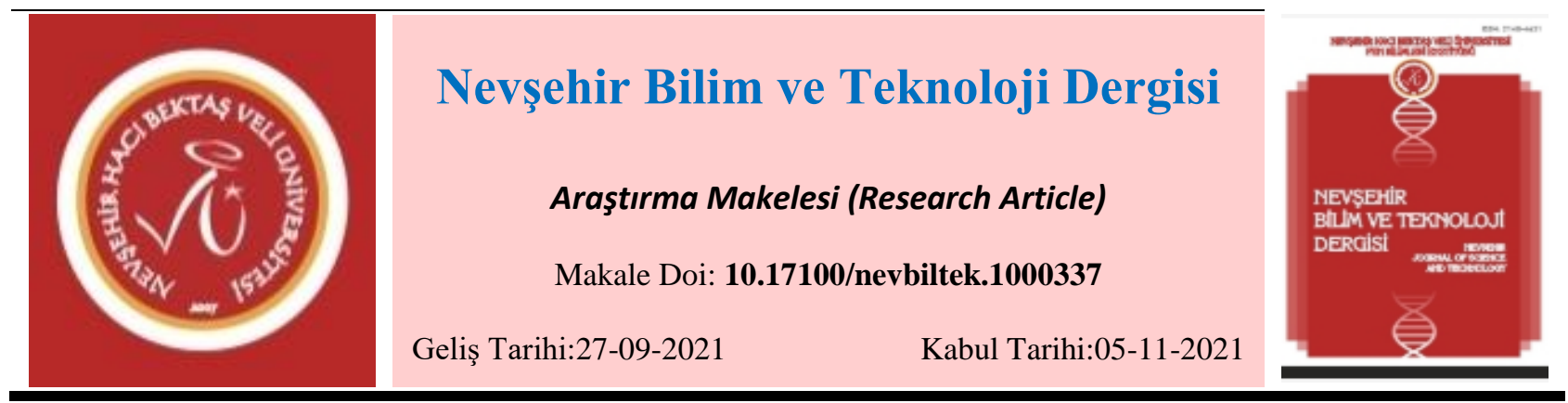

\title{
Reçine 3D yazıcı ürünlerinin biyo-uyumluluk incelemesi
}

\author{
Bünyamin ÇIÇEK *, Tuna AYDOĞMUŞ ${ }^{2}$, Yavuz SUN ${ }^{3}$, \\ ${ }^{1}$ Hitit Üniversitesi, Teknik Bilimler Meslek Yüksekokulu, Makine ve Metal Teknolojileri, Çorum \\ ORCID ID: 0000-0002-6603-7178 \\ ${ }^{2}$ Hitit Üniversitesi, Teknik Bilimler Meslek Yüksekokulu, Elektrik ve Enerji Bölümü, Çorum \\ ORCID ID: 0000-0002-8736-2949 \\ ${ }^{3}$ Karabük Üniversitesi, Mühendislik Fakültesi, Metalürji ve Malzeme Mühendisliği, Karabük \\ ORCID ID: 0000-0002-7336-5591
}

$\ddot{0} \mathbf{z}$

Bu çalışmada katmanlı imalat yönteminin bir uygulaması olarak son yıllarda endüstrideki birçok alanda kullanılan reçine 3D yazıcı kullanılmıştır. UV ışın etkisiyle kürlenen ve sertleşen reçine yapılar prototip üretiminde önemli rol oynamaktadır. Reçine 3D yazıcı ürünlerinin bu çalışmada biyo konusundaki temel incelemesi yapılmıştır. 3D yazıcıda monomer temelli bir epoksi reçineden üretilen bir numunenin önce SEM incelemesi yapılmış ve sonrasında temel biyo - uyumluluğu üzerine çalışma yapılmıştır. Belirli kürleme ve son işlem şartlarında üretilen epoksi reçine ürünün temel biyo uyumluluk incelemesi adına üretilen numunelere sitotoksisite testi uygulanmıştır. L929 hücre tipi kullanılarak canlılık takip edilmiş ve ISO 10993-5 standardı çerçevesinde akredite laboratuvar şartlarında deney yapılmıştır. Uygulanan bu deneyin sonucu olarak malzemenin biyo uyumlu olduğu raporlanmıştır. Deney sonucunda canlılık oranı \%140 olarak elde edilmiştir.

Anahtar Kelimeler: Epoksi reçine; 3D yazıc1; biyo-uygunluk; sitotoksisite.

\section{Biocompatibility investigation of resin 3D printer products}

\begin{abstract}
In this study, as an application of the additive manufacturing method, a resin 3D printer, which has been used in many areas in the industry in recent years, has been used. Resin structures that cure and harden with the effect of UV light wavelength play an important role in prototype production. In this study, a basic review of the resin 3D printer products on bio was conducted. A sample produced from a monomer-based epoxy resin in a 3D printer was first analyzed by SEM and then studied on basic biocompatibility. To examine the basic biocompatibility of the epoxy resin product produced under certain curing and finishing conditions, cytotoxicity test was applied to the produced samples. Viability was monitored using L929 cell type and experiments were carried out in accredited laboratory conditions within the framework of ISO 10993-5 standard. As a result of this experiment, it has been reported that the material is biocompatible. As a result of the experiment, the viability rate was obtained as $140 \%$.
\end{abstract}

Keywords: Epoxy resin; 3D printer; biocompatibility; cytotoxicity.

*Sorumlu yazar: cicekbunyamin78@gmail.com 


\section{Giriş}

Katmanlı imalatın temel çalışma prensibi ile ürün üretebilen reçine tipi 3D yazıcılar son yıllarda sıklıkla kullanılmaktadır. Reçine 3D yazıcılar; klasik filaman üzerinden eritme yaparak ürün elde eden 3D yazıcıların aksine daha iyi yüzey kalitesi ve daha hassas bir geometrik form sağlamaktadır [1,2]. Bu yüzden hassas döküm alanında kalıp olarak ve/veya hızlı üretilmek istenen prototiplerin imalatında kullanılmaktadır [1,3]. Son yıllarda bu epoksi reçine yapılar biyo alanda modelleme ve/veya direk ürün üretiminde kullanılmaktadır [4, 5].

Bazı monomer ve polimerler belli adhesif etkilerle ve/veya aktivatör yapılarla bulunan formlarından daha katı yapılara dönüsşebilmektedirler [1]. Bu etkiler sıcaklık, güneşışı̆̆ı, yapay ışınlar, lazer ışınları ve özel sıvılar olabilmektedir [6]. UV ışınını aktivatör bir etki olarak kabul eden özel reçine sıvılarına belli sürelerde verilen ışın bu reçinenin katılaşmasını sağlamaktadır [7]. UV ışını ile kürlenen bu yapılar katmanı şekilde bir form oluşturabilmektedir [7, 8]. Çünkü UV ışını ile katılaşan ve dolayısıyla kürlenen bu yapılar bir sonraki aşamada tekrar katılaşmaya uygun olamazlar [9]. Böylece katmanların $\mu \mathrm{m}$ seviyesinde oluşması uygulanabilir duruma gelmektedir [9, 10]. Böylece çizim olarak hazırlanan ürünün $\mu \mathrm{m}$ hassasiyetinde üretilmesi mümkün olmaktadır [11].

UV ışınını bir LCD ekran üzerinden " $g$-code” yardımı ile kontrollü şekilde sağlayabilen reçine 3D yazıcılar bu işlemde son yıllarda başarılı bir süreç izlemişlerdir [3, 8]. Her katmanın çizimden gelen detaylarını $\mu$ m ölçüsünde UV ışın demetine ve eşit dalga boyuna çeviren sistemler bir makine halini almıştır [3]. Böylece üretim hızı artmış ve hassasiyet üst seviyelere ulaşmıştır [10,11].

Reçine 3D yazıcı ürünleri hızlı prototipleşme konusunda son yıllarda kullanılmaktadır. Bu hızlı prototipleşme süreci biyo, uzay ve havacılık konularında endüstride kolaylık sağlamaktadır [5, 12, 13]. Bu ürünlerin hammaddesi olan epoksi reçineler ise biyo uyumlu malzemeler olarak bilinmektedir [14-16]. Bu yüzden bu çalışmanın amacında bu iki temel olgunun (hızlı prototip + biyo uyum) birleştirilmesi amaçlanmıştır.

$\mathrm{Bu}$ çalışmada reçine sıvısı üzerinden UV ışını ile katılaştırma yapabilen bir 3D yazıcı kullanılmıştır. Belirlenen UV ışını dalga boyu, ışın bekleme süresi, katman kalınlığı gibi parametrelerin kontrol edilmesi ile dikdörtgen prizmatik bir ürün üretilmiş̧tir. Numunenin katmanlı durumunu izlemek adına SEM incelemesi yapılmıştır. Son olarak üretilen ve kürlenen numunenin biyo uygunluğunu tespit edebilmek için sitotoksisite testi yapılmıştır. Sonuç olarak katmanlı imalat yöntemi ile üretilen numunenin 1/1 konsantrasyonda \%140 seviyesinde \% canlılık gösterdiği tespit edilmiştir.

\section{Materyal ve Metot}

Çalışmamızda kullanılan Creality LDR-002 marka reçine 3D yazıcı ve Dokuz Kimya tarafından üretilen Alias model genel amaçlı epoksi reçine Şekil 1'de gösterilmiştir.

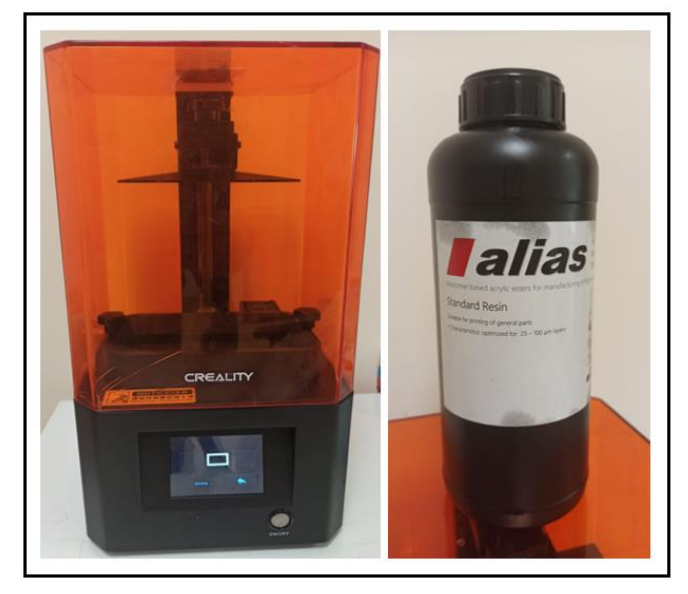

Şekil 1. Çalışmada kullanılan reçine 3D yazıcı ve sıvı reçine 
Nevşehir Bilim ve Teknoloji Dergisi (2021), 10(2) 67-72

Numunelere uygulanacak SEM ve sitotoksisite testlerinin uygulanmasına imkân veren 10x10x20 mm ölçülerinde numuneler üretilmiştir. Çizimler ve yazıcıya aktarma işlemlerinde cihaz firmasına ait "chitubox" yazılımı kullanılmıştır. Üretilen numunelerde $5 \mathrm{~s}$ bekleme süresi ile her basamakta $50 \mu \mathrm{m}$ katman kalınlı̆̆ oluşturulmuştur. Başlangıçtaki ilk 10 katmanda yüzeye tutunması amacıyla bekleme süreleri $10 \mathrm{~s}$ olarak uygulanmıştır. Numuneler de $\% 100$ doluluk seviyesi kullanılmıştır. Bu yöntemle 10 adet numune üretilmiş ve geometrik formu korunan yapılar incelemeye alınmıştır. Elde edilen numuneler $\mathrm{pH}$ oranı 8 olarak ölçülen bir temizleme sıvısında yıkamaya tabi tutulmuştur. Son olarak numuneler 395-400 nm dalga boyuna sahip bir UV LED lamba altında karanlık ortamda ask1 pozisyonunda 600 s kürlenmiştir.

Son aşamada numune SEM çalışmasına alınmak üzere Quorum Q150R ES marka kaplama cihazında $180 \mathrm{~s}$ sürede Pt metali ile kaplanmıştır. SEM incelemesinde farklı büyütmelerde katmanlar izlenmiştir ve rapor edilmiştir.

Numunenin biyo uygunluğu üzerine akredite laboratuvarda sitotoksisite deneyi uygulanmıştır. Test sırasında ISO 10993-12 standardına göre özütleme yapıldı [17]. Numuneler standartta belirtilen miktarda tartılarak serum içermeyen hücre kültürü ortamı içerisinde 24 saat ve $37 \mathrm{C}$ şartlarında $50 \mathrm{rpm}$ hızda salınım yapan su banyosunda bekletildi. $\mathrm{Bu}$ özütleme işlemi sonrasında özüt 24 saat içerisinde kullanıldı. Deney elde edilen özüt ile devam ettirilmiştir. Uygun besi yerinde hücrelerin çoğalması üzerine \% canlılık oranı farklı konsantre derecelerinde rapor edilmiştir. İşlemde hücre hattı olarak L929 cilt altı bağ dokusu hücresi (Fibroblast) ve "American Type Culture Collection (ATCC)" kullanılmıştır. Deneyde hücre vasatı ise "DMEM ( $1 \mathrm{gr} / \mathrm{L}$ glukoz) + L-Glutamin+pirlvat+fetal bovine serum+penisilin+streptomisin" bileşimi olarak uygulanmıştır. Deney sırasında rapor edildiğine göre pozitif kontrol olarak doğal kauçuk kullanılırken negatif kontrol için PE polimeri işleme alınmıştır. Pozitif ve negatif kontrollerde oluşan koloni sayımları dikkate alınarak numunenin \% canlılık oranı elde edilmiştir. Sitotoksisite testi akredite olarak hizmet veren Hitit Üniversitesi HÜBTUAM araştırma merkezinde yaptırılmıştır.

\section{Bulgular}

Epoksi reçinenin UV ışını ile katılaştırılması sonucu elde edilen numunelere ait SEM görüntüleri Şekil 2'de farklı büyütmelerde verilmiştir. Katman kalınlıkları da SEM ortamında ölçülmüştür.

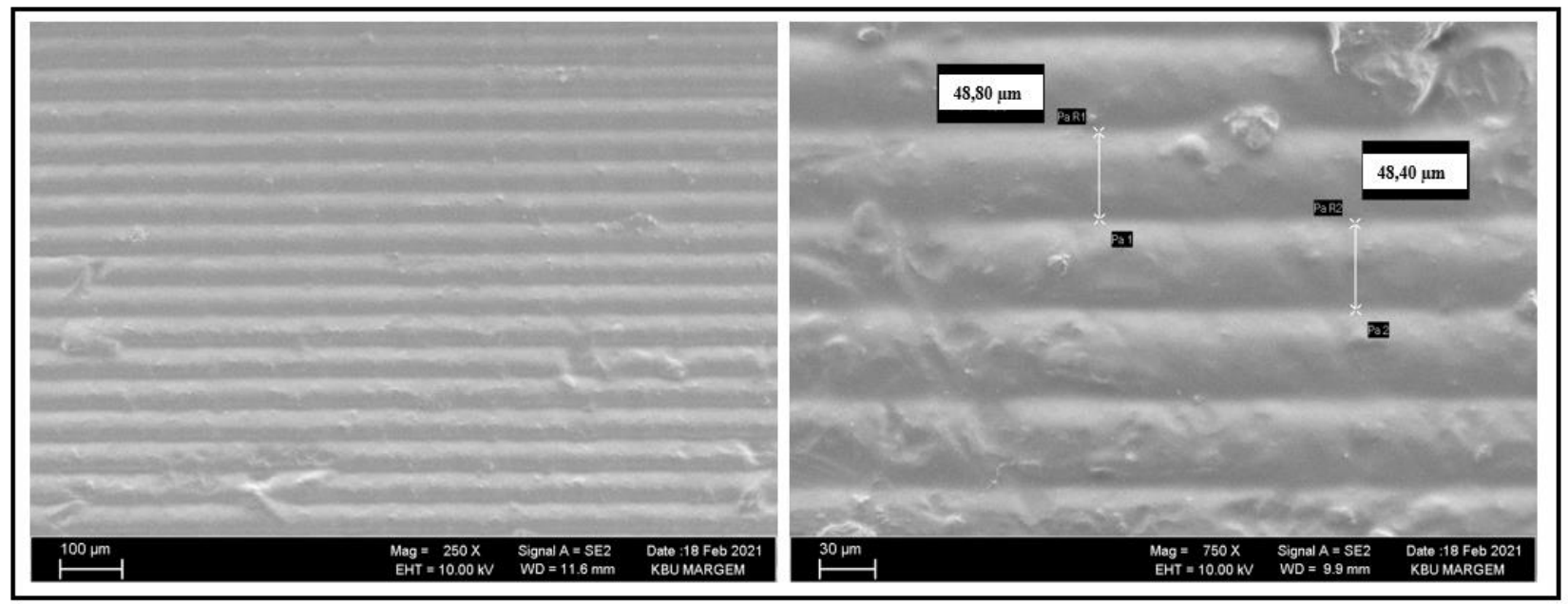

Şekil 2. Farklı büyütmelerde katmanlı numunenin SEM görüntüleri ve katman kalınlığı ölçümü

Numuneler üzerinden alınan SEM görüntülerinde yüzeyin temiz ve harici bir yap1 olmaksızın oluştuğu görülmüştür. Katman kalınlıklarının birbirine yakın kalınlık miktarı gösterdiği izlenmiştir. $50 \mu \mathrm{m}$ olarak hazırlanan 
Nevşehir Bilim ve Teknoloji Dergisi (2021), 10(2) 67-72

çizimlerde $\% 5$ oranında katman kalınlığı farkı oluştuğu görülmektedir. Katmanların birbirine boşluksuz bağlandığı ve süreklilik izlediği sonucuna varılmıştır.

Biyo uygunluk incelemesi sonucunda elde edilen preparat hücre görüntüsü ve \% canlılık oranlarını gösteren grafik Şekil 3’te verilmiştir.
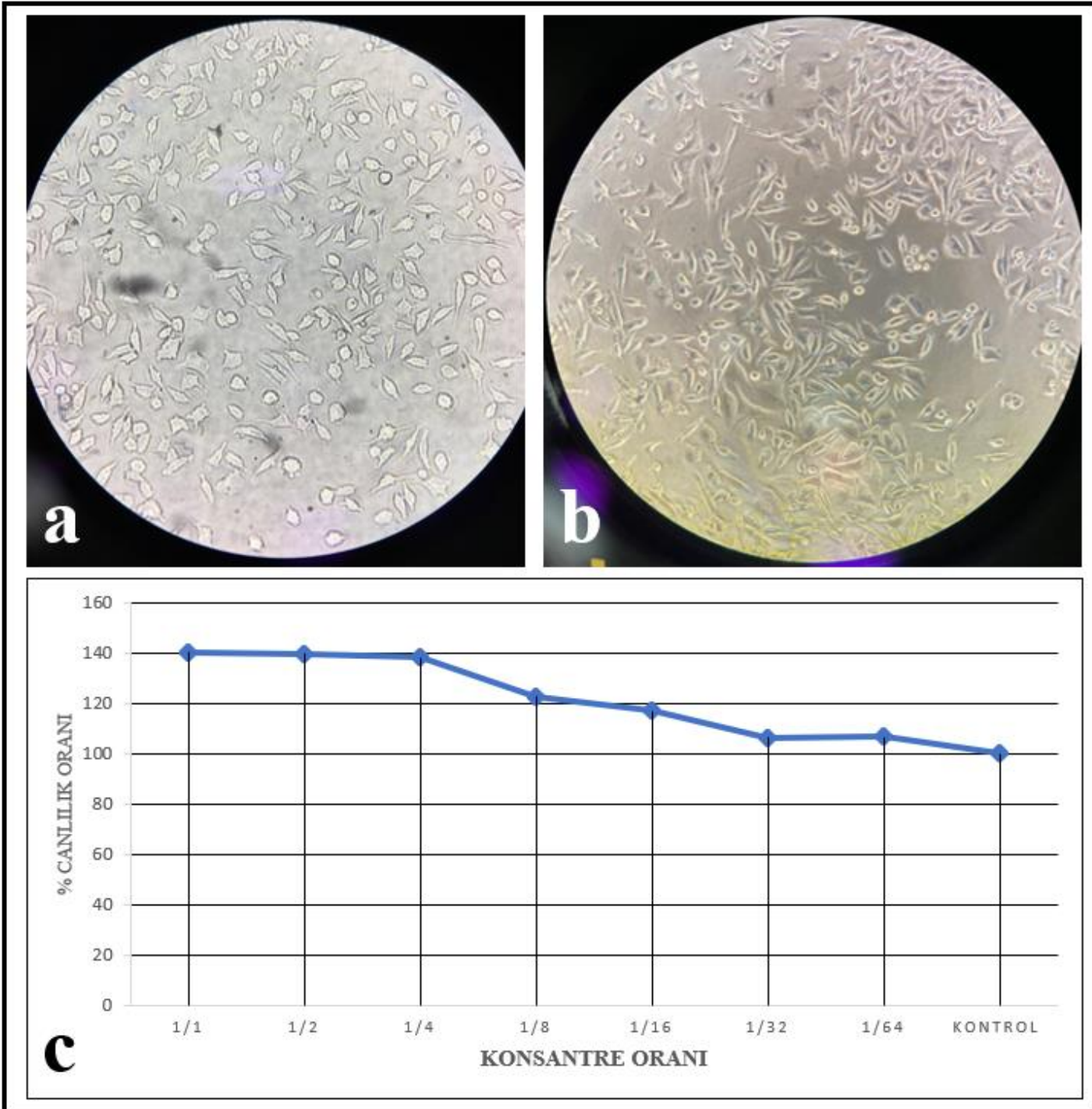

Şekil 3. Sitotoksisite testi sonuçları (a) Deney öncesi preparat görüntüsü, (b) Deney sonrası preparat görüntüsü ve (c) \% canlılık oranı

Sitotoksisite deneyi sonrasında elde edilen preparat görüntülerine göre hücre miktarının artışı net olarak izlenmektedir. \% canlılık oranı ise 1/1 konsantre ortamda \%140 seviyesine kadar çıkmıştır ve hücrelerin çoğaldığ1 görülmüştür. İçerisinde epoksi reçine bekletilen çözeltinin herhangi bir toksik etki oluşturmadığı sonucuna varılmıştır. “TS EN ISO 10993-5/EK-CMTT Sitotoksisite Deneyi” standardı detaylarına göre \% canlılık \%70 ve üzeri değer gösterdiğinde yapı biyo uyumlu kabul edilmektedir [18]. Buradan yola çıkarak deney süresince belirtilen şartlarda üretilen epoksi reçinenin bu şartlarda uygulanan sitotoksisite testi çerçevesinde biyo uyumlu olduğu sonucu elde edilmiştir.

\section{Tartıșma ve Sonuç}

Gelişen teknolojinin içinde yer alan katmanlı imalat teknolojisi aşamasında kullanılan epoksi reçine ürünler bu çalışmada belirli şartlarda üretilmiştir. Üretilen numuneler malzeme bilimi açısından incelenmiş ve biyo uyumlulukları üzerine çalışmalar yapılmıştır. 
Nevşehir Bilim ve Teknoloji Dergisi (2021), 10(2) 67-72

Numunelerin üretimi sonrasında elde edilen SEM resimlerine bakıldığında literatürde yer alan bazı makalelere göre benzer mikro görüntüler elde edilmiştir [2, 3, 7, 19]. Katmanlar arası birleşmelerin sürekli ve boşluksuz oluşmasıı da kabul edilebilir bir üretim şartı uygulandığını göstermektedir. Epoksi reçine ile üretilen numunelere uygulanan sitotoksisite testi sonucunda yapının uygulama standardına göre biyo uyumlu olarak raporlandığı görülmüştür. Sitotoksisite testinin biyo uyumluluk üzerine verdiği sonuçlar göz önünde bulundurularak çalışmada hazırlanan numunelerinde biyo ortamlarda kullanılabileceği sonucuna varılmıştır [4, 18, 19].

Bu çalışmada genel sonuç olarak belirtilen şartlarda üretilen katmanlı imalat ürünü epoksi reçinenin biyo uyumlu olduğu görülmüştür. Böylece basit yöntemlerle biyo uyumlu yapıların üretimi ve/veya modellenmesi bu tip 3D yazıcılarla yapılabilecektir.

\section{Teşekkür ve Katkı Beyanı}

Çalışmanın hazırlanması aşamasında yazarlar; B.Ç.: Deneyin düzeneğinin hazırlanması, laboratuvar çalışmaları, raporlama T.A.: Deneyin düzeneğinin hazırlanması, laboratuvar çalışmaları, mizanpaj, raporlama, Y.S.: Raporlama ve yorumlama görevlerinde bulunmuşlardır.

\section{Kaynaklar}

[1] Weng, Z., Zhou, Y., Lin, W., Senthil, T., Wu, L., "Structure-property relationship of nano enhanced stereolithography resin for desktop SLA 3D printer", Composites Part A: Applied Science and Manufacturing, $88,234-242,2016$

[2] Liska, R., Schuster, M., Inführ, R., Turecek, C., Fritscher, C., Seidl, B., Schmidt, V., Kuna, L., Haase, A., Varga, F., "Photopolymers for rapid prototyping", Journal of Coatings Technology and Research, 4, 505-510, 2007

[3] Joseph, V. S., Calais, T., Stalin, T., Jain, S., Thanigaivel, N. K., Sanandiya, N. D., Y Alvarado, P. V., "Silicone/epoxy hybrid resins with tunable mechanical and interfacial properties for additive manufacture of soft robots", Applied Materials Today, 22, 100979, 2021

[4] Zahedi-Tabar, Z., Bagheri-Khoulenjani, S., Mirzadeh, H., Amanpour, S., "3D in vitro cancerous tumor models: Using 3D printers", Medical hypotheses, 124, 91-94, 2019

[5] Mehmet, G., "Biyomedikal Mühendisliğinde Kullanım Amaçlı 3D Yazıcı Geliştirilmesi", International Journal of 3D Printing Technologies and Digital Industry, 2, 85-92, 2018

[6] Can, A., Aslan, İ., "Katmanlı üretim ile elde üretilmiş kum döküm kalıpların incelenmesi", Düzce Üniversitesi Bilim ve Teknoloji Dergisi, 6, 1269-1282, 2018

[7] Borrello, J., Nasser, P., Iatridis, J. C., Costa, K. D., "3D printing a mechanically-tunable acrylate resin on a commercial DLP-SLA printer", Additive manufacturing, 23, 374-380, 2018

[8] Postiglione, G., Natale, G., Griffini, G., Levi, M., Turri, S., "Conductive 3D microstructures by direct 3D printing of polymer/carbon nanotube nanocomposites via liquid deposition modeling", Composites Part A: Applied Science and Manufacturing, 76, 110-114, 2015

[9] Shah, S., Megat-Yusoff, P., Karuppanan, S., Choudhry, R., Ahmad, F., Sajid, Z., Gerard, P., Sharp, K., "Performance comparison of resin-infused thermoplastic and thermoset 3D fabric composites under impact loading", International Journal of Mechanical Sciences, 189, 105984, 2020

[10] Trofimov, A., Le-Pavic, J., Ravey, C., Albouy, W., Therriault, D., Lévesque, M., "Multi-scale modeling of distortion in the non-flat 3D woven composite part manufactured using Resin Transfer Molding", Composites Part A: Applied Science and Manufacturing, 106145, 2020

[11] Zhang, Y., Yin, M.-J., Ouyang, X., Zhang, A. P., Tam, H.-Y., "3D $\mu$-printing of polytetrafluoroethylene microstructures: A route to superhydrophobic surfaces and devices", Applied Materials Today, 19, 100580, 2020 
[12] Chatwin, C., Farsari, M., Huang, S., Heywood, M., Young, R., Birch, P., Claret-Tournier, F., Richardson, J., "Characterisation of epoxy resins for microstereolithographic rapid prototyping", The International Journal of Advanced Manufacturing Technology, 15, 281-286, 1999

[13] Dziubek, T., Oleksy, M., "Application of ATOS II optical system in the techniques of rapid prototyping of epoxy resin-based gear models/Zastosowanie systemu optycznego ATOS II w technikach szybkiego prototypowania modeli kol zebatych otrzymywanych na bazie zywicy epoksydowej", Polimery, 62, 44-53, 2017

[14] Huang, T.-H., Yang, J.-J., Li, H., Kao, C.-T., "The biocompatibility evaluation of epoxy resin-based root canal sealers in vitro", Biomaterials, 23, 77-83, 2002

[15] Cintra, L. T. A., Benetti, F., De Azevedo Queiroz, Í. O., Ferreira, L. L., Massunari, L., Bueno, C. R. E., De Oliveira, S. H. P., Gomes-Filho, J. E., "Evaluation of the cytotoxicity and biocompatibility of new resin epoxybased endodontic sealer containing calcium hydroxide", Journal of endodontics, 43, 2088-2092, 2017

[16] Çelebi, A., Tosun, H., Önçağ, A. Ç., "Hasarlı bir kafatasının üç boyutlu yazıcı ile imalatı ve implant tasarımı", International Journal of 3D Printing Technologies and Digital Industry, 1, 27-35, 2017

[17] Wallin, R. F., "A Practical Guide to ISO 10993-12: Sample Preparation and Reference Materials", MDDI: Los Angeles, CA, USA, 1998

[18] Wallin, R. F., Arscott, E., "A practical guide to ISO 10993-5: Cytotoxicity", Medical Device and Diagnostic Industry, 20, 96-98, 1998

[19] Elomaa, L., Keshi, E., Sauer, I. M., Weinhart, M., "Development of GelMA/PCL and dECM/PCL resins for 3D printing of acellular in vitro tissue scaffolds by stereolithography", Materials Science and Engineering: $\boldsymbol{C}$, 110958,2020 